\title{
НАРОДНОХОЗЯЙСТВЕННЫЕ ПРОБЛЕМЫ
}

\section{Природоохранные системы в периоды экономических спадов}

\author{
(с) 2021 г. И.В. Гордин
}

\author{
И.В. Гордин, \\ Институт программных систем РАН, Переславль-Залесский; e-mail: ivgordin@таil.ru
}

Поступила в редакцию 25.02.2021

\begin{abstract}
Работа выполнена при финансовой поддержке Российского фонда фундаментальных исследований (проект № 20-110-50119).

Аннотация. В неблагоприятных экономических условиях возрастает вероятность отказа от технически сложных, дорогостоящих природоохранных стратегий. Нарастает актуальность компромиссов, синтеза не радикальных, а экономически приемлемых систем. Дается аналитический обзор широкого спектра соответствующих эколого-экономических решений. Имеющийся технологический арсенал разделен в статье на два класса: системы рассеивания и системы концентрирования загрязнений в окружающей среде. В анализе систем рассеивания дана характеристика необходимой транспортной инфраструктуры, специальных устройств и сооружений, интенсифицирующих разбавление загрязнений (массообмен) в природных средах, технологий увеличения ассимиляционного потенциала сред-реципиентов. Мощным фактором рассеивания загрязнений рассмотрена мобильность самих источников выброса. Эффективной технологией рассеивания рассмотрено оптимальное размещение предприятий, поселений на этапе территориального планирования. В качестве неотъемлемого свойства стратегии концентрирования рассмотрены высокие эколого-экономические риски. Охарактеризованы средства снижения рисков. Рассмотрены направления оптимизации территориальных схем размещения объектов. Прогнозируется, что по инерции, и особенно интенсивно в периоды экономической рецессии, движение цивилизации по рассмотренным направлениям будет продолжаться. Констатируется, что в этом движении множество природных объектов уже вышли на необратимые процессы. Анализируется, насколько нерадикальность рассмотренных технологий позволяет им взаимодействовать с радикальными, появляющимися по мере выхода из фаз экономического дефицита. Обобщающим выводом является необходимость рассмотрения любого экономически вынужденного отказа от систем глубокой переработки загрязнений только как временной меры, позволяющей найти радикальные решения или экономические средства для реализации известных радикальных решений.
\end{abstract}

Ключевые слова: экономика природопользования; загрязнение окружающей среды; природоохранные системы; эколого-экономические оптимумы; технико-экономические оптимумы.

Классификация JEL: Q53.

DOI: $10.31857 / \mathrm{S} 042473880014913-3$

Нарастающее загрязнение окружающей среды является все более негативной характеристикой цивилизации (Моисеев, 2003; Гордин, 2007; Ревич, Авалиани, Тихонова, 2004; Яблоков, 2007; Яницкий, 2013; Lanz, 2015). Внимание правительств к проблеме непрерывно нарастает (см. «Об утверждении Национального проекта “Экология”». Указ Президента Российской Федерации от 7 мая 2018 г., № 204; «Directive 2008/98/EC of the European Parliament and of the Council of 19 November 2008 on waste and repealing certain Directives» ${ }^{1}$, «European Commission $>$ Environment $>$ Waste $>$ Prevention» $)^{2}$. Реализация природоохранных программ требует колоссальных вложений (Гурман, Рюмина, 2001; Гусев, 2004; Рюмина, 2009, 2011; Tietenberg, Lewis, 2018). Положение усложняется в периоды экономических спадов. При этом экономия средств достигается за счет отступления от цели охраны природного пространства как единого целого, за счет отодвигания проблемы во времени и с проявлением ее в виде глобального загрязнения, за счет увеличения рисков техногенных аварий, рисков непредвиденных экономических ущербов.

\footnotetext{
${ }^{1}$ Article 3, clause 12-13. Official Journal of the European Communities, November.

${ }^{2}$ CM. http://ec.europa.eu/environment/waste/prevention/practices.htm2019
} 
Таблица 1. Характеристики систем очистки сточных вод промышленности строительных материалов в кризис 1990-х годов

\begin{tabular}{l|c|c|c|c|c|c|c|c}
\hline \multirow{2}{*}{ Сточные воды } & \multicolumn{1}{|c}{ Год } \\
\cline { 2 - 9 } & 1993 & 1994 & 1995 & 1996 & 1997 & 1998 & 1999 & 2000 \\
\hline Требующие очистки, млн м ${ }^{3} /$ год & 191 & 157 & 145 & 135 & 127 & 120 & 127 & 134 \\
Нормативно очищенные, млн м ${ }^{3} /$ год & 34 & 20 & 15 & 12,3 & 12,5 & 8,0 & 4,6 & 4,6 \\
Доля стоков с нормативной очисткой, \% & 17,8 & 12,7 & 10,3 & 9,1 & 9,8 & 6,7 & 3,6 & 3,4 \\
\hline
\end{tabular}

Источник: данные Росстата.

Прежде чем приступить к обзору, отметим, что обращение к рассматриваемым стратегиям, оправданное в периоды экономических трудностей, часто возникает и во времена вполне благополучные. Соблазн экономить на охране природы - болезнь, от которой цивилизация излечивается очень медленно. Существуют и такие сферы деятельности, где проблемы загрязнения окружающей среды всегда решались (или не решались) практически независимо от состояния экономики. Так, при наличии огромных вложений в освоение космического пространства долгое время не считалось нужным решать вопросы космического мусора (Рассел, 2012). Возможна и такая эколого-экономическая ситуация, когда даже при самом бедственном состоянии экономики огромные средства вкладываются в борьбу с загрязнением. Такое положение можно наблюдать, например, в отношении радиоактивных отходов, на обезвреживании которых экономить никто никогда не решится. И даже очень глубокий экономический кризис не остановит необходимого финансирования (Цебаковская, Уткин, Капырин, 2015).

В большинстве же отраслей такой «независимости» природоохранной политики от экономических возможностей нет, а существует широкий спектр различных технологий, конкретный выбор из которых определяется именно состоянием экономики. В фазах экономического подъема обычно страны серьезно задумываются о необходимости принципиальных экологических решений. Наиболее радикальны те стратегии, которые минимизируют само возникновение загрязнений: пересмотр структуры потребления, отказ от экологически вредной продукции и вредных производств, безотходные схемы в производстве и эксплуатации изделий (Акинин, 2011; Гордин, 2020; Рюмина, 2000; Maczulak, 2009). Но на такую радикальность цивилизация выходит далеко не так активно, как необходимо для устойчивого развития. Сегодня экологическую катастрофу сдерживает менее радикальная стратегия - глубокая переработка загрязняющих выбросов (газовых, жидкостных, твердых) специальными химико-технологическими системами, производящими вторичные ресурсы или обеспечивающими безопасный сброс остаточных загрязнений в природные среды-реципиенты (Гринин, Новиков, 2002; Юдин, Потапов, 2018). В периоды экономического спада эффективность переработки загрязнений заметно снижается. Проиллюстрируем эту динамику типичным примером (табл. 1).

Но даже в предельно упрощенных схемах переработки выбросов сохраняется идея разделения загрязненного потока на «вредную» и «полезную» составляющие. Иными словами, генерируя загрязняющие вещества, Цивилизация считает своим долгом преобразовывать их в менее (в той или иной мере) опасные. Именно на такое понимание вины и ответственности источника загрязнения нацелено и современное экологическое право (Васильева, 2004; Жаворонкова, Краснова, 2014; Philippopoulos, 2011). Однако этот императив очень часто игнорируется и поток загрязнений выпускается в окружающую среду вообще без химико-технологической переработки.

С точки зрения экологии вырисовывается следующая цивилизационная парадигма. Удовлетворяя свои потребности, Человечество создало систему, перерабатывающую триллионы тонн природного вещества Земли в вещества, подавляющие Природу и Человека. Для поддержания экологического равновесия необходимо иметь соизмеримую по масштабам, дорогостоящую индустрию переработки этих загрязнений в вещества безвредные. Однако, уклоняясь от этого принципиального решения, Цивилизация создала колоссальную индустрию сброса загрязнений без переработки (с недостаточной переработкой). Огромное разнообразие этих, тоже весьма затратных и технически сложных, решений можно методологически разделить на два класса систем:

1) рассеивания и ассимиляции загрязнений в окружающей среде;

2) концентрирования и консервации, изоляции загрязнений в окружающей среде. 
Именно в периоды экономических трудностей применение этих стратегий резко расширяется (как в автономном варианте, так и в составе других стратегий). При этом в каждом классе есть решения, которые при всей нерадикальности оказываются эффективной тактикой защиты от конкретной экологической угрозы, и есть решения, неприемлемые даже в самой сложной экономической ситуации.

1. Системы рассеивания газовых выбросов. Все системы, решающие локальные экологические проблемы рассеиванием газовых выбросов, уже с прошлого века осознаны человечеством как бумеранг, который возвращается глобальным загрязнением и изменением климата (Будыко, Израэль, 1987; Рамсторф, Шельнхубер, 2009). На борьбу с этой угрозой брошены колоссальные средства. Так, несмотря на усложнившиеся экономические условия, в 2020 г. Германия подтвердила свое решение сокращать выбросы парниковых газов к 2030 г. до 55\% уровня 1990 г. Конкретным выражением этой линии явилась компенсация в 40 млрд евро регионам и компаниям, отключающим ТЭС на буром угле. Однако в целом в периоды экономической рецессии внимание к глобальному загрязнению атмосферы резко падает, каждая страна склоняется к рассеивающим технологиям, защищающим внутренние пространства. И цепь неэффективных решений, от саммита в Рио-де-Жанейро - через Киотский протокол - к Парижскому соглашению, может быть продолжена, все более расширяя спектр негативных процессов.

Очевидными символами масштаба сооружений рассеивания загрязнений в окружающей среде являются трубы промышленных объектов. Приведем параметры самых высотных выпусков газовых выбросов: Экибастузская ГРЭС, Казахстан - высота трубы выпуска в атмосферу 420 м; Металлургический комплекс в Онтарио, Канада - 380 м; ТЭС в Пенсильвании, США 371 м. Также повсеместно построены газоотводящие устройства в жилых массивах: от индивидуального сельского сектора - до многоэтажной городской застройки. При невысоком расположении источников промышленных и хозяйственно-бытовых газовых выбросов загрязняется не только атмосфера, но и все наземные объекты, а также прилегающая гидросфера, почва и растительность.

Системы газового выброса оснащаются все более эффективными системами очистки, но в периоды недофинансирования эти прогрессивные тенденции прерываются (Хомич, 2002; Цыплакова, Потапов, 2012; Юшин, 2005). Сегодня мы критикуем мусоросжигательные заводы как недопустимую альтернативу мусороперерабатывающим предприятиям с генерацией вторичных ресурсов, но завтра, возможно, придется считать благом сжигание мусора на заводах с минимальной фильтрацией, но высокими трубами выпуска, защищающими пространство хотя бы в радиусе 2-3 км. Более того, в вариантах нарастания экономических проблем есть все основания прогнозировать, что расширится применение технологий сжигания производственных отходов, твердых бытовых и коммунальных отходов (ТБО и ТКО) на открытом воздухе. В условиях непрекращающегося захламления территорий эффективными системами сжигания мусора и рассеивания газовых выбросов окажутся мобильные колесные крематоры, обеспечивающие грубую сортировку «топлива» и простейшую очистку отходящих газов.

Выхлопы продуктов сгорания на транспорте (Павлова, 2000) являются технологией рассеивания, многократно интенсифицированной мобильностью самих источников загрязнения. На примере углекислого газа назовем доли мобильных «рассеивателей» загрязнения в атмосфеpe. В небе над Землей одновременно находится от 10 до 20 тысяч самолетов. Они дают около 2,2\% всего антропогенного углекислого газа, выбрасываемого цивилизацией в атмосферу. Значительно больше вбрасывает автомобильный транспорт (около 14\%); на железнодорожный, морской и прочие виды транспорта в сумме приходится 3,8\% выбросов.

2. Системы рассеивания жкиких выбросов. Рассеивание сточных вод в гидросфере реализуется технически аналогично атмосферному рассеиванию газовых выбросов (Аксенов, 2007; Воронов и др., 2007). Однако в сравнении с газовыми и твердыми выбросами поступление сточных вод в окружающую среду отличается очень высокой степенью неконтролируемости (Гордин, 2006). Экологические риски усугубляются тем, что водовыпуск может осуществляться предельно скрыто: неучтенные затопленные выпуски, потайные врезки высокотоксичных производственных канализаций в хозяйственно-бытовые и ливневые и многие другие обращения к методам типа «концы в воду». В сельской местности широко распространен развоз откаченных отходов автоцистернами. Эта технология предполагает выгрузку ассенизационных машин на приемных пунктах поселковых и городских очистных сооружений, но зачастую производится скрытый спуск в болота, водотоки и водоемы. Мощнейшей составляющей неконтролируемого 
рассеивания загрязняющих веществ в гидросфере и литосфере является талый и дождевой поверхностный смыв с промышленных площадок, городских территорий, сельхозугодий, застраиваемых побережий.

Для сосредоточенных источников загрязнения типовым природоохранным решением является трубопроводная перекачка стоков с заводских и городских очистных сооружений к местам выпуска в сравнительно безопасные створы, расположенные вниз по течению от жилых массивов или уникальных природных объектов. Рекордным по масштабам строительства в этом классе технологий явился проект сброса сточных вод Байкальского ЦБК не в озеро, а через водораздел в бассейн реки Иркут по трубопроводу длиной 80 км. Широко распространены по всему миру выпуски сточных вод (очень часто не проходящих даже простейшие очистные сооружения) в моря и океаны.

Спецификой рассеивания сточных вод в гидросфере является возможность целенаправленного повышения ассимиляционного потенциала принимающих водотоков и водоемов. Это - переброска речного стока в маловодные бассейны, увеличение разбавляющей способности рек путем строительства регулирующих гидроузлов. В таких проектах увеличения рассеивающего потенциала окружающей среды фигурируют многомиллиардные затраты. К этому же подклассу решений, но с гораздо меньшими затратами, относятся методы интенсификации внутриводоемных процессов самоочищения различными аэраторами, фитоактиваторами, специальной ихтиофауной и др.

В качестве среды-реципиента для рассеивания сточных вод широко используется литосфера, верхние слои которой обладают свойствами механического фильтра, испарителя, почвеннорастительного биореактора (Андроханов, Куляпина, Курачев, 2004; Carre et al., 2017).

3. Системы рассеивания твердых выбросов. Огромные массы твердофазного загрязнения рассеиваются в атмосфере (Архипов, Шереметьева, 2007). Они являются отходами добычи полезных ископаемых, металлургии, производств строительных материалов (цемента, кирпича, керамики) и других промышленных предприятий, котельных (особенно угольных и мазутных), уходят в воздух пылью от автомобильных дорог (асфальта, резины) и других объектов.

Твердая фаза различных загрязнений в огромных масштабах распространяется в гидросфере. Так, повсеместным способом поддержания экологического равновесия является удаление загрязнений (включая крупнодисперсные) в виде организованной (поливомоечной) или неорганизованной (тало-дождевой) промывки территорий. Столь же значительна роль гидросферы и в удалении аэрозольного загрязнения. Этот процесс особенно заметен, когда атмосферные взвеси выпадают и накапливаются всю зиму в снежном покрове площади водосбора, превращаясь весной в рекордно загрязненные потоки талых вод. Одновременно в гидросферу поступают огромные массы загрязняющей взвеси, послойно накопившиеся зимой в снежно-ледовом покрове водных объектов. Сюда же прибавляется регулярный сброс «черного снега», убираемого с городских территорий и промышленных площадок.

Огромная часть процессов рассеивания твердых выбросов в окружающей среде является предельно антиэкологичной. Безудержное увеличение числа свалок представляет собой процесс опасного стихийного рассеивания вместо продекларированного вывоза с безопасным концентрированием и изоляцией. Сегодня в РФ насчитывается около 15 тысяч санкционированных свалок отходов производства и потребления, примерно столько же - крупных нелегальных. Суммарная площадь крупных свалок и полигонов составляет около 4 млн га, и она прирастает со скоростью 0,3-0,4 млн га/год. В этой же логике неуправляемого процесса рассеивания с каждой новой свалки происходит дальнейшее рассеивание отходов, но уже - в атмосфере (посредством стихийного горения и организованного поджога), гидросфере и литосфере (путем поверхностного смыва и инфильтрации в грунтовые воды).

Перейдем к обзору систем концентрирования и консервации, изоляции загрязнений.

1. Системы концентрирования газовых выбросов. Примером позитивного концентрирования газовых выбросов является сосредоточение в одном месте множества источников загрязнения атмосферы, изначально разбросанных по территории. Когда, например, тысячи горящих и тлеющих свалок заменяются выбросом газов мощного мусоросжигательного завода с глубокой очисткой.

Специфичной является проблема концентрирования газовых выбросов в городских и поселковых отопительных системах (Магадеев, 2013; Трухний, 2008; Кувшинов, Ливчак, 2012). Еще совсем недавно централизация признавалась здесь оптимальным технико-экономическим решением, 
основанным на утилизации сбросного тепла ТЭЦ. Но сегодня и в промышленном, и в гражданском строительствах явно прослеживается тенденция децентрализации систем теплоснабжения и горячего водоснабжения. Хотя не вызывает сомнения, что проблема обезвреживания продуктов горения эффективнее решается именно в схеме концентрирования. Вместе с тем, такая экологизация теплоснабжения, получившая мощное развитие в советское время, является огромным наследством, поддерживать которое в исправном состоянии оказывается крайне трудно. Дефициты региональных и муниципальных бюджетов могут стать здесь серьезным препятствием, вполне вероятно, - даже главным испытанием для российской системы ЖКХ.

Коснемся кратко мобильных источников загрязнения атмосферы. Если авиацию, железнодорожные магистрали, дальние морские рейсы можно без оговорок считать технологиями рассеивания газовых выбросов в атмосфере, то автомобильный транспорт городов одновременно стал и крайне опасной технологией концентрирования выбросов на ограниченной территории. Не менее специфичен и переход к электротранспорту (Кашкаров, 2018). Рассмотрение этой тенденции в аспекте рассеивания-концентрирования имеет следующие основания и методологические преимущества. Апологеты экологических автомобильных электродвигателей называют их главным достоинством минимизацию загрязнения окружающей среды. Сторонники углеводородных двигателей аргументировано возражают, обращая внимание на тот факт, что основная доля в выработке электроэнергии принадлежит электростанциям с колоссальными газовыми выбросами в атмосферу. Но необходима третья точка зрения - оценка ситуации в координатах «рассеивание-концентрирование». И здесь мы четко видим, что парк традиционных автомобилей является «идеальной системой» опасного рассеивания вредных выбросов в приземных слоях атмосферы городских агломераций, он вносит свой огромный вклад в глобальное загрязнение. Концентрирование позволяет надежно контролировать исправность фильтрующего оборудования в процессе эксплуатации, что нереально для ускользающих от контроля автомобилей с индивидуальными фильтрами.

2. Системы концентрирования жидких выбросов. Эти накопительные системы всегда рассматривались как вынужденное, экстенсивное решение, требующее свободных земельных ресурсов. Широко применяется концентрирование промышленных стоков и шламов (Чертес, Тупицына, Пыстин, 2015; Guyer, 2018). Здесь на первый план выходит железобетонное строительство и многократно усложняющиеся вопросы донной гидроизоляции и конструктивной прочности. Характеризуют это технологическое направление исключительно высокие экологические риски. Напомним только два прорыва накопителей шламов в центре Европы.

В январе 2000 г. в г. Байя-Маре (Румыния) произошел прорыв дамбы накопителя и выброс 100 тыс. т промышленных отходов, в том числе цианидов и тяжелых металлов. В Тисе предельно допустимые концентрации (ПДК) цианистых соединений оказались превышены в 2000 раз. Только в Венгрии вышли из строя водозаборы городов с населением 2,5 млн человек. В венгерских водах погибло до 85-90\% животных и растений. Затем отравленная вода подошла к Югославии с 20-50-кратным превышением ПДК по металлам и цианидам. В сербской части Тисы погибло 80\% рыбы, а также огромное число птиц и животных. Всего из Тисы было извлечено около 650 т погибшей рыбы. Опасное загрязнение зафиксировано далее на всем протяжении Дуная до Черного моря. В сентябре 2010 г. в г. Айка (Венгрия) разрушилась дамба шламонакопителя алюминиевого завода с прорывом в окружающую среду более миллиона кубометров отходов. Шламовый поток разрушил мосты и дома, смыл сотни автомобилей. Были затоплены несколько населенных пунктов, слой красного шлама на их территории достигал глубины до двух метров. В результате катастрофы 10 человек погибли, 120 серьезно пострадали, в основном из-за химических ожогов. И хотя огромные силы были брошены, чтобы остановить распространение катастрофы, ядовитые химикаты попали в Дунай, нанеся огромный ущерб Хорватии, Сербии, Румынии и Болгарии.

На отечественных накопителях сточных вод и шламов также регулярно происходят аварии. К примеру, в том же 2010 г. произошло следующее. Прорыв дамбы шламонакопителя ООО «Аммофос» (Вологодская область): ущерб от загрязнения окружающей среды (бассейн Рыбинского водохранилища) - 17,8 млн руб. Прорыв дамбы шламонакопителя Абагурского филиала ОАО «Евразруда» (Кемеровская область): ущерб (р. Кондома) - 927,2 млн руб. Эти ущербы, конечно, не сравнить с аварией на «Норникеле» в 2020 г., вызванной прорывом 21 тыс. т дизельного топлива и приведшей к ущербу в 147,7 млрд руб. Полезно сопоставить: добывая и перерабатывая нефть, создали потребительскую ценность в 40 руб./кг, которая нанесла ущерб в 7033 руб./кг. 
Таблица 2. Генерация ТКО и роль различных технологий обращения с ними, 2014-2015 гг.

\begin{tabular}{l|c|c|c|c}
\hline Страны & $\begin{array}{c}\text { Общий объем генерации } \\
\text { ТКО, млн т/год }\end{array}$ & $\begin{array}{c}\text { Доля отходов, } \\
\text { размещаемых } \\
\text { на полигонах, } \%\end{array}$ & $\begin{array}{c}\text { Доля сжигаемых } \\
\text { отходов, \% }\end{array}$ & $\begin{array}{c}\text { Доля отходов, } \\
\text { перерабатываемых } \\
\text { вороричные ресурсы, } \%\end{array}$ \\
\hline США & 289,2 & 52,5 & 12,8 & 34,7 \\
ЕС & 252 & 28 & 27 & 44 \\
Германия & 38,1 & $<1$ & 34 & 66 \\
Норвегия & 2,3 & 3,1 & 56,9 & 34,2 \\
Финляндия & $2,4-2,8$ & 3,2 & 54,7 & 42,1 \\
Китай & 203,62 & 60,2 & 30 & Нет данных \\
\hline
\end{tabular}

Источник: по материалам (Вахрушева, 2018).

3. Системы концентрирования твердых выбросов. Остановимся только на наиболее обсуждаемой экологической проблеме последнего десятилетия - захоронении ТКО на полигонах (Варенчев, Потапов, Щетинина, 2018; Гордин, 2019; Коробко, Бычкова, 2012; Duan, Scheutz, Kjeldsen, 2020). Какова судьба действующих полигонов? Станет ли полигонов больше, если сократятся средства, выделяемые на сферу обращения с отходами?

Сначала посмотрим, куда в принципе мы могли бы прийти вслед за развитыми странами. Естественно, что отечественных экологов вдохновляют высокотехнологичные зарубежные решения по переработке и утилизации ТБО-ТКО. Тем более что для установки рекордов переработки не обязательно входить в число наиболее развитых стран. Так, например, первое место в мире по переработке алюминиевых банок занимает Бразилия, которая повторно использует $98,2 \%$ этого вида ТБО. Также нельзя не заметить, что даже в развитых странах большую роль играют самые примитивные технологии обращения с отходами. Проанализируем выборку по материалам (Вахрушева, 2018), представленную в табл. 2.

Все представленные страны располагают современными высокими технологиями в сфере переработки мусора и значительными финансовыми возможностями. Но можно заметить, что структура технологических стратегий во многом определена не этими факторами, а располагаемыми земельными ресурсами и климатом. В США и Китае более $50 \%$ отходов идет на полигоны (часто - на свалки, не менее чудовищные, чем в России). Страны, отличающиеся высокой окультуренностью территории (Германия, Норвегия, Финляндия), находятся по этому параметру в рамках 3,2\%. Общая для ЕС доля строительства полигонов резко нарастает до $28 \%$ за счет европейских стран с более небрежным отношением к земельным ресурсам, но все равно далека от показателей США и Китая. Норвегия и Финляндия лидируют по сжиганию ТБО-ТКО, что однозначно связано со стремлением максимально восполнить дефицит энергии в условиях холодного климата. Территориальноэнергетический дефицит заставляет Японию сжигать (плазменной газификацией) $69 \%$ ТКО.

В Российской Федерации образуется около 60 млн т ТКО/год. Из них на промышленную переработку и утилизацию поступает только 4,5 млн т/год, т.е. 7,5\%; промышленно сжигается около 3\%; на полигонах и свалках накапливается (и тоже зачастую горит) около $90 \%$ ТКО. Экономически вынужденное строительство полигонов должно стать глубоко продуманным в плане использования природных преимуществ России и неравномерности распределения жителей по территории страны. И чтобы не утратить эти преимущества и социальное равновесие в результате нерациональных действий, необходимо искать возможность совершенствовать технологии строительства и эксплуатации полигонов даже в условиях серьезных экономических трудностей. При этом очень важно отметить, что никакие экономические аргументы не мешают развивать систему раздельного сбора. У нас есть огромные резервы оптимизации этого процесса, которые вполне могут вывести если не на цифры, близкие к данным табл. 2, то на рывок с 7,5 до 15-20\% перерабатываемых и утилизируемых отходов.

Проведенный обзор дает широкую картину экономически мотивированного уклонения Цивилизации от необходимости обезвреживания своих отходов, антиэкологичного сброса их в атмосферу, гидросферу и литосферу. При этом подавляющая масса (и тоннажная, и ассортиментная) продуктов потребления вырабатывается из литосферы с интенсивным вовлечением в технологические процессы водных ресурсов. Сброс производственных и бытовых отходов в атмосферу и гидросферу уже привел к ряду глобальных последствий, критических для жизни на планете. На этом фоне размещение отходов в литосфере, несмотря на широчайший спектр негативных последствий, следует 
признать меньшей экологической угрозой. Вырисовывается фундаментальная закономерность, по которой минимизацией экологической опасности является твердофазная генерация отходов и их локализованный сброс в литосферу - возвращение в базовую среду генерации производственного сырья. При этом нет сомнений, что и на этом направлении Цивилизацию без принятия экстренных мер защиты, без технологического прорыва ждет экологический коллапс. Эти меры должны базироваться на эффективной сортировке, переработке и утилизации отходов в народном хозяйстве, специальной переработке оставшихся объемов в материалы, наносящие минимальный экологический вред в процессе литосферного разложения или литосферной консервации.

Рассмотренные технологии экономии средств на решении природоохранных проблем рано или поздно приводят к огромным потерям и в экологическом, и в экономическом плане. Но также несомненно, что Цивилизация по инерции, и особенно интенсивно в периоды экономической рецессии, будет продолжать двигаться по этим направлениям. Есть основания констатировать, что в этом движении планета уже сегодня в ряде сфер вышла на необратимые процессы деградации природной среды. Вместе с тем, многие из рассмотренных технологий могут (часто без значительных модернизаций и дополнительных затрат) эффективно взаимодействовать с радикальными, появляющимися по мере выделения средств (например, строительство мусороперерабатывающего завода при полигоне ТКО). Главное, чтобы любая замена систем глубокой химико-технологической переработки загрязнений системами рассеивания и концентрирования рассматривалась только как временный щит, благодаря которому удастся найти лучшие решения или экономические средства для реализации известных радикальных решений.

\section{СПИСОК ЛИТЕРАТУРЫ / REFERENCES}

Акинин Н.И. (2011). Промышленная экология: принципы, подходы, технические решения. М.: Изд. РХТУ им. Д. Менделеева. [Akinin N.I. (2011). Industrial ecology: Principles, approaches, technical solutions. Moscow: D. Mendeleev University of Chemical Technology of Russia (In Russian).]

Аксенов В.И. (2007). Водное хозяйство промышленных предприятий. М.: Теплотехник. 239 с. [Aksenov V.I. (2007). Water management of industrial enterprises. Moscow: Teplotekhnik. 239 p. (In Russian).]

Андроханов В.А., Куляпина Е.Д., Курачев В.М. (2004). Почвы техногенных ландшафтов: генезис и эволюция. Новосибирск: Изд-во СОРАН. 151 с. [Androkhanov V.A., Kulyapina E.D., Kurachev V.M. (2004). Soils of man-made landscapes: Genesis and evolution. Novosibirsk: SB RAS. 151 p. (In Russian).]

Архипов В.А., Шереметьева У.М. (2007). Аэрозольные системы и их влияние на жизнедеятельность. Томск: Изд. ТомГПУ. 136 с. [Arkhipov V.A., Sheremetyeva U.M. (2007). Aerosol systems and their impact on life. Tomsk: Tomsk SPU. 136 p. (In Russian).]

Будыко М.И., Израэль Ю.А. (1987). Антропогенные изменения климата. Ленинград: Гидрометеоиздат. 406 с. [Budyko M.I., Izrael Yu.A. (1987). Anthropogenic climate change. Leningrad: Gidrometeoizdat. 406 p. (In Russian).]

Варенчев А.А., Потапов И.И., Щетинина И.А. (2018). Проблема твердых бытовых отходов: обзор // Экономика природопользования. № 2. С. 53-62. [Varenchev A.A., Potapov I.I., Schetinina I.A. (2018). Solid waste: Overview. Nature Management Economics, 2, 53-62. (In Russian).]

Васильева М.И. (2004). Правовые проблемы организации управления в сфере окружающей среды. М.: Акрополь. 254 c. [Vasilyeva M.I. (2004). Legal problems of environmental governance. Moscow: Akropol. 254 p. (In Russian).]

Вахрушева К.А. (2018). Международный экологический обзор // Экология и право. № 72. С. 26-34. [Vakhrusheva K.A. (2018). International environmental review. Ecology and Law, 72, 26-34. (In Russian).]

Воронов Ю.В., Алексеев Е.В., Саломеев В.П., Пугачев Е.А. (2007). Водоотведение. М.: ИНФРА М. 415 с. [Voronov Yu.V., Alekseev E.V., Salomeev V.P., Pugachev E.A. (2007). Water disposal. Moscow: INFRA-M. 415 p. (In Russian).]

Гордин И.В. (2007). Игнорирование экологических угроз. М.: Физматлит. 120 c. [Gordin I.V. (2007). Ignoring of ecological threats. Moscow: Fizmatlit. 120 p. (In Russian).]

Гордин И.В. (2006). Кризис водоохранных зон России. М.: Физматлит. 196 с. [Gordin I.V. (2006). Crisis of water protection zones of Russia. Moscow: Fizmatlit. 196 p. (In Russian).]

Гордин И.В. (2020). Современные стратегии сокращения отходов // Экономическая наука современной России. № 3. C. 95-109. [Gordin I.V. (2020). Modern waste reduction strategies. Economics of Contemporary Russia, 3, 95-109. (In Russian).]

Гордин И.В. (2019). Теоретические предпосылки технологического прорыва в сфере обезвреживания ТКО // Управление экономическими системами: Электронный научный журнал. № 6. [Gordin I.V. (2019). Theoretical prerequisites 
for technological breakthrough in the field of solid municipal waste processing. Management of Economic Systems: Scientific Electronic Journal, 6. (In Russian).]

Гринин А.С., Новиков В.Н. (2002). Промышленные и бытовые отходы: хранение, утилизация, переработка. М.: Фаир-Пресс. 336 с. [Grinin A.S., Novikov V.N. (2002). Industrial and household waste: Storage, utilization, processing. Moscow: Fair-Press. 336 p. (In Russian).]

Гурман В.И., Рюмина Е.В. (ред.) (2001). Моделирование социо-эколого-экономической системы региона. М.: Наука. 175 c. [Gurman V.I., Ryumina Ye.V. (eds.) (2001). Modelling of the socio-ecological-economic system of the region. Moscow: Nauka. 175 p. (In Russian).]

Гусев А.А. (2004). Современные экономические проблемы природопользования. М.: Международные отношения. 208 c. [Gusev A.A. (2004). Modern economic problems of environmental management. Moscow: International Relations. 208 p. (In Russian).]

Жаворонкова Н.Г., Краснова И.О. (2014). Экологическое право. М.: Проспект. 376 с. [Zhavoronkova N.G., Krasnova I.O. (2014). Environmental legislation. Moscow: Prospect. 376 p. (In Russian).]

Кашкаров А.П. (2018). Современные электромобили. М.: ДМК-Пресс. 91 с. [Kashkarov A.P. (2018). Modern electric vehicles. Moscow: DMK-Press. 91 p. (In Russian).]

Коробко В.И., Бычкова В.А. (2012). Твердые бытовые отходы. Экономика. Экология. Предпринимательство. М.: ЮНИТИ-ДАНА. 131 с. [Korobko V.I., Bychkova V.A. (2012). Municipal solid waste. Economy, ecology, business. Moscow: UNITY-DANA. 131 p. (In Russian).]

Кувшинов Ю.Я., Ливчак И.Ф. (2012). Развитие теплоснабжения, климатизации и вентиляции в России. М.: АСВ. 366 c. [Kuvshinov Yu. Ya., Livchak I.F. (2012). Development of heat supply, climatization and ventilation in Russia. Moscow: ASV. 366 p. (In Russian).]

Магадеев В.Ш. (2013). Источники и системы теплоснабжения. М.: Энергия. 272 с. [Magadeev V. Sh. (2013). Heat supply sources and systems. Moscow: Energija. 272 p. (In Russian).]

Моисеев Н.Н. (2003). Междисциплинарные исследования глобальных проблем. М.: ТайдексKo. 264 c. [Moiseev N.N. (2003). Interdisciplinary research on global issues. Moscow: Tidex Co. 264 p. (In Russian).]

Павлова Е.И. (2000). Экология транспорта. М.: Транспорт. 248 с. [Pavlova E.I. (2000). Ecology of transport. Moscow: Transport. 248 p. (In Russian).]

Рамсторф Ш., Шельнхубер Х. (2009). Глобальное изменение климата: диагноз, прогноз, терапия. М.: Изд-во ОГИ. 272 c. [Ramstorf Sh., Shelnkhauber Ch. (2009). Global climate change: Diagnosis, prognosis, therapy. Moscow: OGI. 272 p. (In Russian).]

Рассел Дж. (2012). Космический мусор. М.: Озон. 70 с. [Rassel J. (2012). Space waste. Moscow: Ozon. 70 p. (In Russian).]

Ревич Б.А., Авалиани С.Л., Тихонова Г.И. (2004). Экологическая эпидемиология. М.: Изд. Центр «Академия». 344 с. [Revich B.A., Avaliani S.L., Tikhonova G.I. (2004). Environmental epidemiology. Moscow: Center «Academy». 344 p. (In Russian).]

Рюмина E.B. (2000). Анализ эколого-экономических взаимодействий. М.: Наука, 2000. 158 с. [Ryumina Ye.V. (2000). Analysis of environmental-economic interactions. Moscow: Nauka. 158 p. (In Russian).]

Рюмина Е.В. (2011). Экологические издержки экономики. М.: Изд-во МБА. 111 с. [Ryumina Ye.V. (2011). Environmental costs of economy. Moscow: MBA. 111 p. (In Russian).]

Рюмина Е.В. (2009). Экономический анализ ущерба от экологических нарушений. М.: Наука. 330 c. [Ryumina Ye.V. (2009). Economic analysis of environmental damage. Moscow: Nauka. 330 p. (In Russian).]

Трухний А.Д. (2008). Основы современной энергетики. М.: Изд. дом МЭИ. 472 с. [Trukhniy A.D. (2008). Fundamentals of modern energy. Moscow: MEI. 472 p. (in Russian).]

Хомич В.А. (2002). Экология городской среды. Омск: Изд. СибАДИ. 267 с. [Homich V.A. (2002). Ecology of the urban environment. Omsk: SibADI. 267 p. (In Russian).]

Цебаковская Н.С., Уткин С.С., Капырин И.В. (2015). Обзор зарубежных практик захоронения ОЯТ и РАО. М.: Комтехпринт. 208 с. [Cebakovskaya N.S., Utkin S.S., Kapyrin I.V. (2015). Review of foreign practices in the burial of spent nuclear fuel and radioactive waste. Moscow: Komtehprint. 208 p. (In Russian).]

Цыплакова Е.Г., Потапов А.И. (2012). Оценка состояния и управление качеством атмосферного воздуха. СПб.: Нестор-История. 580 с. [Cyplakova E.G., Potapov A.I. (2012). Assessment and management of atmospheric air quality. Saint Petersburg: Nestor-Istorija. 580 p. (In Russian).]

Чертес К.Л., Тупицына О.В., Пыстин В.Н. (2015). Геоэкологическая оценка накопителей шламов водного хозяйства и разработка технологий их ликвидации // Вестник МГСУ. № 2. C. 110-129. [Chertes K.L., Tupitsina O.V., Pystin V.N. (2015). Geoecological assessment of water management sludge accumulators and development of technologies for their elimination. Bulletin of MGSU, 2, 110-129. (In Russian).] 
Юдин А.Г., Потапов И.И. (2018). Кризис с отходами: европейский выход - «циркулярная экономика» // Экономика природопользования. № 5. C. 45-50. [Yudin A.G., Potapov I.I. (2018). Waste Crisis: European exit — circular economy. Nature Management Economics, 5, 45-50. (In Russian).]

Юшин В.В. (2005). Техника и технология защиты воздушной среды. М.: Высшая школа. 391 c. [Yushin V.V. (2005). Air protection technique and technology. Moscow: Higher School. 391 p. (in Russian).]

Яблоков А.В. (2007). Россия: здоровье среды и людей. М.: Яблоко. 200 с. [Yablokov A.V. (2007). Russia: Environmental and human health. Moscow: Yabloko. 200 p. (In Russian).]

Яницкий О.Н. (2013). Экологические катастрофы: структурно-функциональный анализ // Институт социологии РАН. Электронный ресурс. 258 c. URL: http://www.isras.ru/publ.html?id=2794 [Yanitskiy O.N. (2013). Environmental disasters: Structural and functional analysis. Institute of Sociology of the Russian Academy of Sciences. 258 p. (In Russian).]

Carre F., Caudeville J., Bonnard R., Bert V., Boucard P., Ramel M. (2017). Soil contamination and human health: A major challenge for global soil security. Global Soil Security. Springer International Publishing Switzerland, 275-295.

Duan Z., Scheutz C., Kjeldsen P. (2020). Trace gas emissions from municipal solid waste landfills: A review. Waste Management, 119, 39-62.

Guyer J.P. (ed.) (2018). An introduction to wastewater sludge disposal. Independently published.

Lanz T.J. (2015). Global environmental problems: Causes, consequences, and potential solutions. $1^{\text {st }}$ ed. San-Diego: Cognella Academic Publishing.

MaczulakA.E. (2009). Waste treatment: Reducing global waste (green technology). Facts on File. Illustrated edition. New York: Infobase Publishing.

Philippopoulos A. (2011). Law and ecology: New environmental foundations. 1st ed. London: Routledge.

Tietenberg T.H., Lewis L. (2018). Environmental and natural resource economics. 11th ed. London: Routledge.

\title{
Environmental protection systems during periods of economic downturns
}

(C) 2021 I.V. Gordin

\author{
I.V. Gordin, \\ A.C. Ailamazjan Program Systems Institute RAS, Pereslavl'-Zalesskii, Russia; e-mail: ivgordin@mail.ru
}

Received 25.02.2021

This work was financially supported by the Russian Foundation for Basic Research (project No. 20-110-50119).

Abstract. In the unfavorable economic environment, the likelihood of abandoning technically complex, expensive environmental strategies increases. The urgency of compromises, the synthesis of not radical, but economically acceptable systems, is growing. An analytical review of a wide range of relevant environmental and economic solutions is given. The available technological arsenal is divided into two classes in the article: systems for the dispersion and concentration of pollutants in the environment. The analysis of dispersion systems describes the necessary transport infrastructure, special devices and structures that intensify mass transfer in natural environments, and technologies to increase their assimilation potential. The mobility of the emission sources themselves is considered a powerful factor in the dispersion of pollutants. The optimal placement of enterprises and settlements at the stage of territorial planning is considered by the effective technology of dispersion. High environmental and economic risks are considered as an integral feature of the concentration strategy. Optimal schemes for placing objects are considered. It is predicted that by inertia, and especially intensively during periods of economic recession, the movement of civilization in the considered directions will continue. It is stated that in this movement, many natural objects have already reached irreversible ecological degradation processes. It is analyzed to what extent the non-radicality of the considered technologies allows them to interact with the radical ones that appear as they exit the phase of economic deficits. A generalizing conclusion is the need to consider any economically forced abandonment of deep pollution processing systems only as a temporary measure that allows us to find radical solutions or economic means to implement known radical solutions.

Keywords: nature management economics, environmental pollution, environmental protection systems, ecological and economic optima, technical and economic optima.

JEL Classification: Q53.

DOI: $10.31857 / \mathrm{S} 042473880014913-3$ 